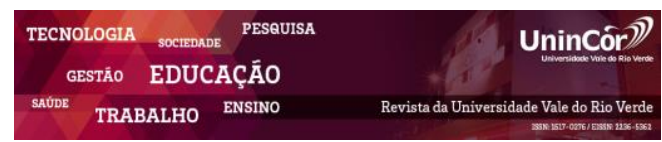

Revista da Universidade Vale do Rio Verde ISSN: 1517-0276 / EISSN: 2236-5362 v. 17 | n. 1 | Ano 2019

Mohamed Ziad Dabaja

Universidade Federal de Alfenas spfc_mohamed@hotmail.com

Amanda Varano

Universidade Federal de Alfenas amandah.varano@hotmail.com

Gustavo Silveira

Universidade Federal de Alfenas gustavo.silveira@unifal-mg.edu.br

Masaharu Ikegaki

Universidade Federal de Alfenas masaharu.ikegaki@unifal-mg.edu.br

Ernandes Benedito Pereira Universidade Federal de Alfenas, Programa de Pós Graduação em Engenharia Química ernandes.pereira@unifal-mg.edu.br

\section{AVALIAÇÃO DA ATIVIDADE ENZIMÁTICA DE FUNGO ENDOFÍTICO ISOLADO DE Annona crassiflora (MAROLO) COM INTERESSE BIOTECNOLÓGICO.}

\section{RESUMO}

Os micro-organismos endofíticos são fungos e bactérias encontrados no interior de tecidos e órgãos saudáveis das plantas e que não causam danos aparentes aos hospedeiros durante o ciclo vital in vivo. Os fungos endofíticos são capazes de produzir substâncias de interesse biotecnológico, sendo que algumas enzimas possuem aplicações em processos industriais. A espécie Annona crassiflora, conhecida popularmente como marolo ou pinha do cerrado, é uma árvore nativa e exclusiva do cerrado brasileiro, amplamente difundido em todo o bioma. É encontrada e abrangem os estados de São Paulo, Minas Gerais, Bahia, Mato Grosso do Sul, Mato Grosso e Tocantins. Nesse contexto, o presente trabalho avaliou o potencial biocatalítico de enzimas produzidas por fungos endofíticos isolados de Annona crassiflora aplicadas em reações de biotransformação.

Palavras-chave: Biotransformação, Atividade Enzimática, Marolo, Fungos endofíticos.

\section{EVALUATION OF THE POTENTIAL FOR PRODUCTION OF ENZYMES OF INTEREST IN BIOTECHNOLOGY BY FUNGI ENDOPHYTIC FUNGI ISOLATED FROM Annona crassiflora (MAROLO).}

Endophytic microorganisms are fungi and bacteria found within healthy tissues and organisms of plants and do not cause apparent damage to hosts during the life cycle in vivo. Endophytic fungi are capable of producing substances of biotechnological interest, and some enzymes have applications in industrial processes. Annona crassiflora, also known as 'marolo' or 'pinha-do-cerrado' is a tree native to the Brazilian Cerrado, widely spread throughout the biome. The species spans across the states of São Paulo, Minas Gerais, Bahia, Mato Grosso do Sul, Mato Grosso and Tocantins. It is a fruit that is inserted in the food and culture of the savanna populations, with a unique identity, being appreciated in the manufacture of liqueurs, juices, ice cream, cakes, savory dishes and sweets. In this context, this study aims to evaluate the potential of biocatalytic enzymes produced by endophytic fungi isolated from Anonna crassiflora applied in biotransformation reactions.

Keywords: Biotransformation, Enzymatic Activity, Marolo, Endophytic Fungi. 


\section{INTRODUÇÂO}

É enorme a lista de enzimas de interesse biotecnológico produzidos por endofíticos. Entre elas estão às amilases, proteases, quitinases, celulases, lipases e muitas outras que possuem potencial para serem empregadas em diferentes funções industriais. As aplicações das enzimas no mercado industrial visam à melhoria de processos, aumentando sua eficiência, e a obtenção de produtos de melhor qualidade, reduzindo custos de produção e a inserindo produtos de forma mais acessível para a população (NETO, 2001). A produção industrial de enzimas utilizando microorganismos é um dos principais setores da Biotecnologia, sendo que as proteases ocupam o primeiro lugar no mercado internacional de enzimas, seguido das amilases (MICHELIN, 2005). A produção de enzimas por fungos endofíticos ocorre principalmente durante a infecção do fungo na planta (BATEMAN, 2001). Entretanto, a produção enzimática por fungos endofíticos é variável, dependendo da especificidade entre a planta hospedeira e o fungo (TAN e ZOU, 2001). Por exemplo, os fungos endofíticos podem parasitar os fitopatogênicos e nesse processo há a liberação de enzimas hidrolíticas como quitinases e proteases, que atuam diretamente sobre o patógeno, degradando as paredes celulares de suas hifas (AZEVEDO e ARAÚJO, 2002). É possível identificar também a produção de enzimas líticas, como pectinases, celulases e lipases no processo de entrada dos endofíticos no tecido vegetal por aberturas naturais ou artificiais (POLIZELI, 1991). Ainda que o Brasil importe grande parte de suas enzimas, o país tem um potencial gigantesco para ser auto-suficiente, pois é abundante em matéria orgânica existente que poderia ser utilizada como substrato de baixo custo para fermentações. Além disso, o Brasil apresenta a maior biodiversidade do mundo, que pode ser explorada para a descoberta de novos fungos endofíticos produtores de enzimas de interesse industrial (DO CANTO e MENEZES, 1995). Objetivou-se com esse trabalho caracterizar a atividade das enzimas amilolíticas, celulolíticas, lipolíticas e esterásicas, em linhagens fúngicas endofíticas de Annona crassiflora e avaliar a bioprospecção dessas enzimas de com potencial de interesse biotecnológico.

\section{MATERIAL E MÉTODOS}

Obtenção dos fungos endofíticos de Annona crassiflora

As 43 culturas de fungos endofíticos isolados de Annona crassiflora foram obtidas no Laboratório de Bioprocessos da Universidade Federal de Alfenas e foram utilizados em todas as reações de caracterização enzimática.

\section{Reativação dos fungos endofíticos}

Devido ao longo tempo sem repique, as 43 culturas previamente isoladas, que estavam armazenadas em tubos de ensaio e em estufa de BOD (Demanda Bioquímica de Oxigênio) a $28^{\circ} \mathrm{C}$, identificou que todas as culturas estavam escassas de meio de cultivo. Desta forma, optou-se em 
reativá-las novamente utilizando $15 \mathrm{~mL}$ de extrato de malte $2 \%(\mathrm{~m} / \mathrm{v})$, e colocando-as na estufa (BOD) a $28^{\circ} \mathrm{C}$ num período de 6 dias. Após esse período, os fungos foram transferidos dos tubos de ensaio para placas de Petri, utilizando-se meio ágar-malte $2 \%(\mathrm{~m} / \mathrm{v})$, para a confirmação do isolamento de cada cultura. Após o isolamento, todos os testes enzimáticos foram realizados com os fungos retirados dessas placas com todas as devidas precauções para se evitar qualquer tipo de contaminação.

\section{Transferências das culturas}

As transferências dos fungos das placas de Petri contendo as culturas isoladas para os meios específicos para realização dos testes enzimáticos foram realizadas com o auxílio de uma alça de aço inoxidável. Deste modo, cortouse um fragmento do meio de cultura que continha alta densidade celular, posicionando-se e pressionando esse fragmento sobre o meio enzimático escolhido.

\section{Determinação da atividade enzimática}

As metodologias descritas a seguir foram selecionadas pela facilidade da técnica, material e equipamentos disponíveis no laboratório, sendo que outros procedimentos estão disponíveis na literatura. Nesse caso foi utilizada a técnica de agar cup plate que é baseada na introdução da amostra no centro de uma placa de Petri, contendo meio ágar juntamente com o inóculo do micro-organismo alvo. As placas foram incubadas por 24 horas e observou-se a presença ou ausência do halo de inibição. Todos os meios de cultivo foram esterilizados via calor úmido em autoclave $\left(121^{\circ} \mathrm{C} / 1 \mathrm{~atm} / 15 \mathrm{~min}\right)$ antes de serem utilizados para inoculação.

\section{Atividade amilolítica}

Os micro-organismos cresceram em meio ágar-malte $2 \%$ e $1 \%$ de amido solúvel (v/v). Após o crescimento microbiano foram adicionados 10 $\mathrm{mL}$ de solução de iodo e lavados imediatamente com água. A presença de um halo incolor em torno da colônia indica a produção de amilases (HANKIN e ANAGNOSTAKIS, 1975).

\section{Atividade celulolítica}

Os micro-organismos cresceram em meio ágar-malte $2 \% \quad(\mathrm{~m} / \mathrm{v}) \quad$ e $\quad 1 \% \quad$ de carboximetilcelulose solúvel (v/v). Após o crescimento microbiano foram adicionados $10 \mathrm{~mL}$ de solução de iodo e lavados imediatamente com água. A presença de um halo incolor em torno da colônia indica a produção de celulase (TEATHER e WOOD, 1982).

\section{Atividade lipolítica}

A atividade lipolítica foi determinada pela presença de lipase empregando-se meio de cultura contendo $2 \%$ de ágar $(\mathrm{m} / \mathrm{v}), 1 \%$ de peptona $(\mathrm{m} / \mathrm{v})$, 0,5\% de $\mathrm{NaCl}, 0,01 \%$ de $\mathrm{CaCl}_{2}$. Após a esterilização do meio foi adicionado $1 \%(\mathrm{v} / \mathrm{v}) \mathrm{de}$ Tween 20, previamente esterilizado. Então, inocularam-se as culturas no meio. A presença de halos formados por cristais indica a produção de lipase pelas linhagens inoculadas (SIERRA, 1957). 


\section{Atividade esterásica}

A metodologia utilizada para a produção de esterase foi idêntica da utilizada para a lipase, sendo substituído o Tween 20 pelo Tween 80 na mesma proporção. A produção de esterase é indicada pela presença de halos claros ao redor do micro-organismo (SIERRA, 1957).

\section{Atividade de fosfato inorgânico - fosfatases}

A atividade de fosfato inorgânico foi realizada inoculando os micro-organismos em meio de fosfato insolúvel, contendo: $10 \%$ de glicose, $5 \%$ de cloreto de amônio, $1 \%$ de $\mathrm{NaCl}$, $1 \%$ de sulfato de magnésio hidratado, $0,8 \%$ de $\mathrm{Na}_{2} \mathrm{HPO}_{4}, 2 \%$ de ágar em $\mathrm{pH} 7,2$. As placas foram incubadas em BOD a $28{ }^{\circ} \mathrm{C}$ e visualizadas com a presença de halo ao redor das colônias capazes de solubilizar fosfato (VERMA et al., 2001, RODRIGUEZ et al., 2000).

\section{Atividade de fosfato $\beta$-fructofuranosidase}

A atividade da $\beta$-fructofuranosidase foi utilizada um meio rico em sacarose com a seguinte composição $(0,1 \%$ de uréia, $10 \%$ de sacarose, $1 \%$ de extrato de levedura. Após o preparo do meio, $15 \mathrm{~mL}$ do mesmo foram transferidos para erlenmeyers previamente identificados pra cada uma das culturas dos fungos. Em seguida, os mesmos foram inoculados em cada um dos erlenmeyers e levados a um shaker de bancada, permanecendo por 4 dias/ 28 ${ }^{\circ} \mathrm{C}$. Após 4 dias de fermentação, $1 \mathrm{~mL}$ do sobrenadante de cada erlenmeyer foi retirado e transferido para um eppendorf. Os eppendorfs foram centrifugados por $5 \mathrm{~min} / 115 \mathrm{rpm}$. Após essa etapa, foi realizada a cromatografia em papel, com o objetivo de verificar qualitativamente a presença da substância $\beta$ fructofuranosidase através da cor da mancha.

\section{Fermentação submersa}

Após a análise qualitativa da atividade enzimática foi selecionada a enzima que teve maior produção, sendo essa selecionada para o ensaio fermentativo. Desta forma, o fungo foi cultivado em placas de Petri com meio contendo batata dextrose ágar, sendo que os fragmentos da cultura com alta densidade celular foram transferidos para erlenmeyers de 1L contendo $100 \mathrm{~mL}$ de inóculo (2\% de peptona, $0,05 \%$ de $\mathrm{NaNO}_{3}, 0,1 \%$ de extrato de levedura, $1 \%$ de óleo de oliva e $0,05 \%$ de $\mathrm{MgSO}_{4}$ ). O inóculo foi mantido por $48 \mathrm{~h}$ no shaker sob agitação de 542 rpm a uma temperatura de $28^{\circ} \mathrm{C}$. Após esse tempo, $5 \mathrm{~mL}$ do inóculo foi transferido para erlenmeyers de $250 \mathrm{~mL}$, onde foram adicionados $45 \mathrm{~mL}$ do meio de cultivo ( $3 \%$ de peptona, $0,05 \%$ de $\mathrm{NaNO}_{3}, 0,1 \%$ de extrato de levedura, $1,5 \%$ de óleo de algodão e $0,05 \%$ de $\mathrm{MgSO}_{4}$ ). $\mathrm{O}$ cultivo foi mantido por $72 \mathrm{~h}$ nas mesmas condições do

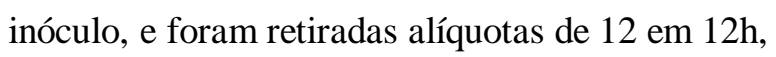
para controle de $\mathrm{pH}$, peso seco e dosagem de atividade enzimática.

Determinação da atividade enzimática na fermentação

A atividade hidrolítica presente no caldo, foi determinada pela hidrólise do azeite de oliva $(\mathrm{m} / \mathrm{v})$ em emulsão de acordo com metodologia adaptada de Soares et al. (1999). O substrato foi preparado pela mistura $(1: 1)$ de $50 \mathrm{~mL}$ do azeite 
de oliva com $50 \mathrm{~mL}$ de solução de goma arábica $7 \%(\mathrm{~m} / \mathrm{v})$ como agente emulsificante em tampão fosfato de sódio $100 \mathrm{mM} \mathrm{pH} \mathrm{7,0.} \mathrm{Foram}$ adicionados em erlenmeyers de $125 \mathrm{~mL}, 5 \mathrm{~mL}$ da emulsão, $4 \mathrm{~mL}$ do tampão fosfato e $1 \mathrm{~mL}$ do caldo de fermentação, incubados a $37^{\circ} \mathrm{C}$, por 5 min, com agitação de $200 \mathrm{rpm}$. A reação foi interrompida com a adição de solução de acetonaetanol $(1: 1 \mathrm{v} / \mathrm{v})$ e foi feita a titulação com solução $200 \mathrm{mM}$ de $\mathrm{NaOH}$. A atividade enzimática (A) foi calculada através da equação:

$$
A=\frac{\left(V_{A}-V_{B}\right) * 1000 * M N a O H}{(C f * t)}
$$

em que $\mathrm{V}_{\mathrm{A}}$ é o volume de $\mathrm{NaOH}$ gasto na amostra em $\mathrm{mL} ; \mathrm{V}_{\mathrm{B}}$ é o volume médio de $\mathrm{NaOH}$ gasto nos brancos em mL; $\mathrm{M}_{\mathrm{NaOH}}$ é a molaridade da solução em mol/L; $C_{\mathrm{f}}$ é o volume do caldo de fermentação; t é o tempo de reação em min.

\section{RESULTADOS E DISCUSSÃO}

\section{Reativação dos Fungos Endofíticos}

De maneira geral, os fungos compõem o grupo microbiano com maior número de espécies e apresentam imensa variedade quanto à morfologia e quanto aos atributos fisiológicos e bioquímicos. Isso tem propiciado ao homem explorar algumas linhagens fúngicas que apresentam capacidade de produzir enzimas com diversas aplicações industriais. No entanto, a preservação adequada desses micro-organismos visando à manutenção das suas características originais por longos períodos de tempo é de suma importância para sua aplicação em pesquisas e desenvolvimento dos processos biotecnológicos, garantindo a reprodutibilidade dos resultados (COLEN, 2006; TORRES et al., 2008). Devido ao grande tempo sem o repique das linhagens para novos tubos de ensaios com meios de cultura ricos em nutrientes, apenas 23 das 43 culturas foram reativadas. As 20 linhagens que não foram reativadas morreram devido à escassez de nutrientes no meio onde se encontravam e foram devidamente descartadas.

\section{Caracterização Enzimática}

\section{Atividade amilolítica}

A habilidade de degradar amido foi usada como critério para determinação da produção de enzimas amilolíticas. As amilases são um grupo de hidrolases que catalisam as ligações $\alpha$ glicosídicas em amido e estão entre as enzimas de maior importância para a biotecnologia, encontrando demanda industrial crescente. Através da seleção primária em ágar amido não foi possível detectar a formação de halos de hidrólise. Portanto, das 23 culturas testadas, nenhuma delas produziu amilase. Também foi observado que, após a formação do complexo amido-lugol, não houve a presença de halo incolor ao redor das colônias, confirmando que não houve a produção de amilase, pois essa enzima iria atuar na degradação do amido, gerando espaços onde não haveria amido para o lugol se complexar.

\section{Atividade celulolítica}

Em relação à prospecção de celulase, 7 das 23 linhagens $(30,43 \%)$ foram capazes de produzir essa enzima. $\mathrm{O}$ resultado positivo pode ser visualizado na Figura 1. A presença de halos incolores ao redor das colônias indica a degradação da carboximetilcelulose, expressando a atividade celulolítica dos fungos endofíticos 
isolados de Annona crassiflora. Neste caso, as enzimas excretadas pelas linhagens fúngicas degradaram a carboximetilcelulose que havia no meio de cultura, impossibilitando a formação do complexo carboximetilcelulose-lugol.

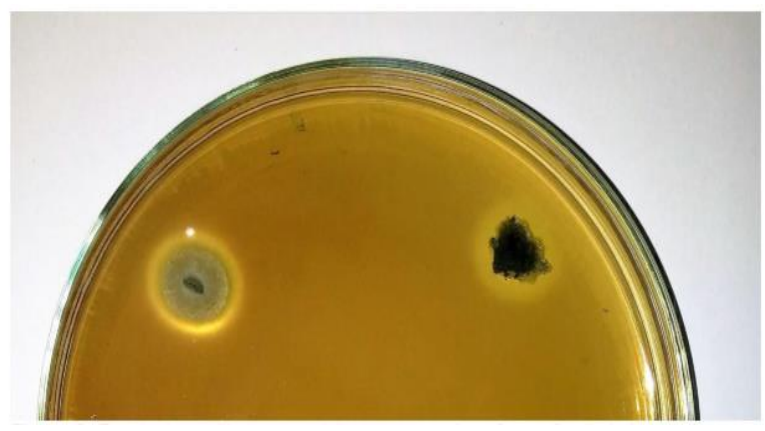

Figura 1 - Resultado positivo para celulase, mostrando a formação de halos incolores ao redor das colônias.

\section{Atividade lipolítica}

Das 23 culturas prospectadas, 18 delas produziram lipase $(78,26 \%)$. O resultado positivo dessa enzima pode ser observado na Figura 2. A presença de cristais ao redor das colônias indica a insolubilidade do sal de cálcio sobre o ácido graxo gerado pelas lipases.

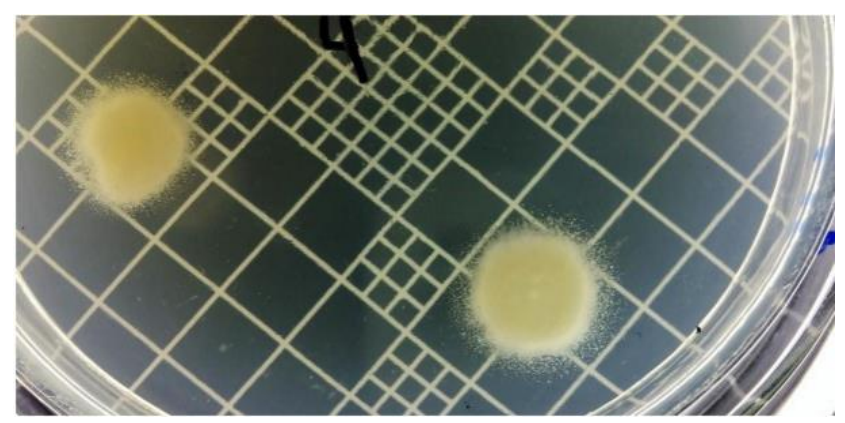

Figura 2 - Resultado positivo para lipase, mostrando a formação de cristais ao redor das colônias.

\section{Atividade esterásica}

Em relação à prospecção de esterases, apenas 2 das 23 culturas $(8,69 \%)$ produziram essa enzima. O resultado positivo para esterases pode ser observado na Figura 3. A presença de halos incolores ao redor das colônias indica a liberação de ácidos graxos produzido pelas esterases.

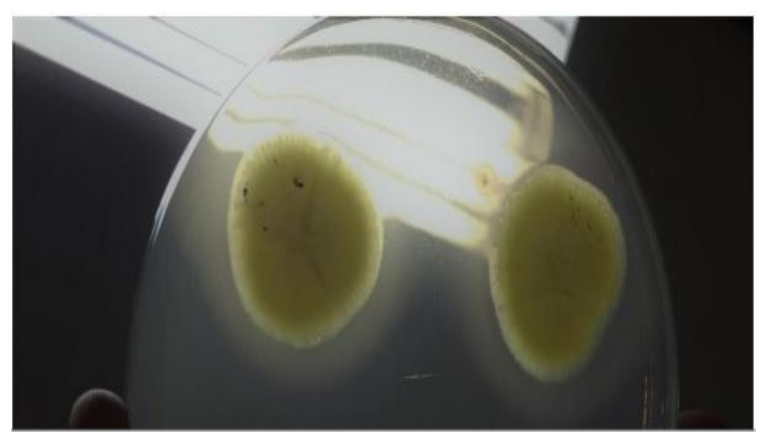

Figura 3 - Resultado positivo para esterases, mostrando a presença de halos ao redor das colônias.

\section{Atividade de fosfato inorgânico - fosfatases}

Das 23 culturas avaliadas, 17 delas produziram fosfatases $(73,91 \%)$. O resultado positivo para essa enzima pode ser visualizado na Figura 4. A solubilização do fosfato inorgânico no meio de cultura indica a produção de fosfatases pelas linhagens testadas.

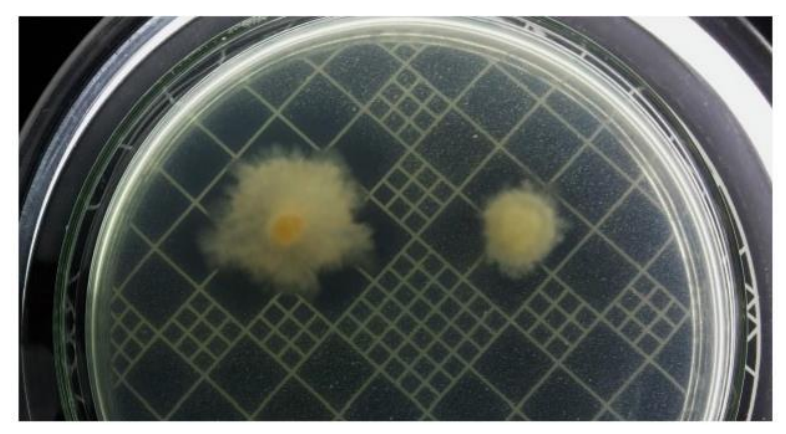

Figura 4 - Resultado positivo para fosfatase, mostrando a solubilização do fosfato inorgânico ao redor das colônias.

\section{Atividade de $\beta$-fructofuranosidase}

Em relação à produção de $\beta$ fructofuranosidase, 21 das 23 linhagens $(91,30 \%)$, produziram essa enzima, gerando glicose e/ou frutose. Além disso, 5 das 21 linhagens produtoras de $\beta$-fructofuranosidase foram capazes de produzir um trissacarídeo gerado pelo complexo sacarose-glicose ou sacarose-frutose. $\mathrm{O}$ resultado positivo para essa 
enzima pode ser observado na Figura 5, realizado em cromatografia de papel. A presença de bandas que correspondem aos padrões de glicose e frutose indicando a quebra da sacarose pela $\beta$ fructofuranosidase. Além disso, o resultado positivo pode ser observado também pela presença de uma banda mais pesada que a sacarose, representando o trissacarídeo acima explicado.

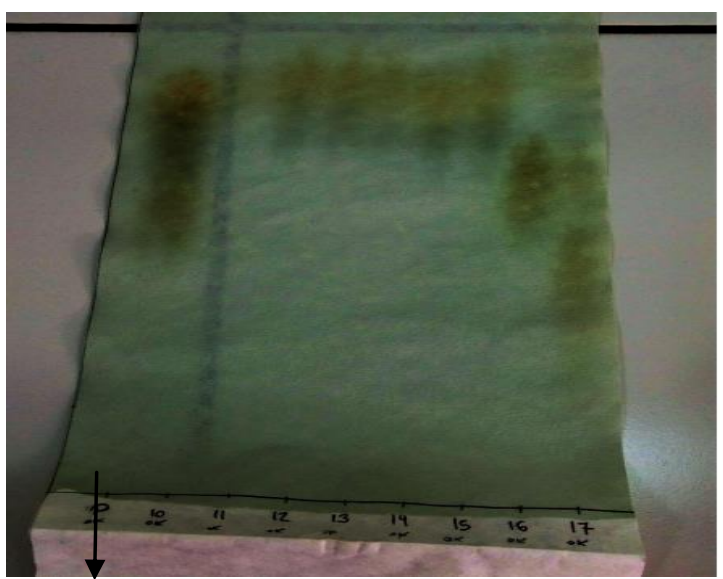

Figura 5 - Resultados positivos para $\beta$ fructofuranosidase $(10,11,12,13,14,15,16,17)$, mostrando a degradação da sacarose gerando glicose e/ou frutose.

A letra "P" mostrada na Figura 5 representa os padrões de sacarose, glicose e frutose, enquanto os números 11 a 17 representam algumas amostras das linhagens testadas. A partir dessa figura, é possível identificar que existem 425 carboidratos que foram eluídos em tempos diferentes podendo ser resumidos pela Figura 6 .

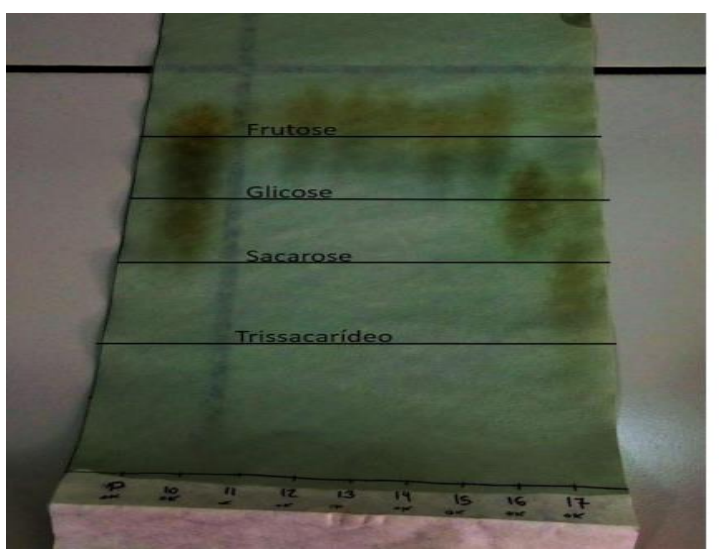

Figura 6 - Resumo dos carboidratos gerados no teste para $\beta$-fructofuranosidase eluídos por cromatografia em papel.

As linhagens de fungos endofíticos isolados de Annona crassiflora se mostraram muito eficientes na produção das enzimas prospectadas, produzindo 5 das 6 enzimas testadas, representadas na Tabela 1 . Um fato muito interessante observado nesse projeto foi que duas das 23 linhagens estudadas produziram as 5 enzimas encontradas (SN2 e 2-16-6), indicando o enorme potencial desses micro-organismos pouco explorados.

Tabela 1 - Representação das enzimas produzidas (colunas) pelas linhagens de fungos endofíticos testadas (linhas). (+) Produção da enzima pela linhagem testada. (-) Não produção da enzima pela linhagem testada. (++) Produção do trissacarídeo pelas linhagens testadas no teste de $\beta$ fructofuranosidase.

\begin{tabular}{|c|c|c|c|c|c|c|}
\hline & Amilase & Celulase & Lipase & Esterase & Fosfatase & $\begin{array}{c}\beta- \\
\text { fructofuranosidase }\end{array}$ \\
\hline SN2 & - & + & + & + & + & + \\
\hline $2-12-1$ & - & - & + & - & + & + \\
\hline $2-14-1$ & - & + & + & - & + & + \\
\hline $2-16-1$ & - & - & - & - & - & - \\
\hline $2-16-6$ & $\cdot$ & + & + & + & + & + \\
\hline $2-18-3$ & - & + & - & - & - & + \\
\hline $2-18-5$ & - & - & - & - & - & - \\
\hline $2-19-1$ & - & - & - & - & - & + \\
\hline $2-20-1$ & - & + & - & - & - & + \\
\hline $2-20-7$ & - & - & + & - & + & + \\
\hline $4-16-4$ & - & - & + & - & + & ++ \\
\hline 4-16-7 C & - & - & + & - & + & ++ \\
\hline $4-16-7 \mathrm{~F}$ & - & - & + & - & + & ++ \\
\hline 4-17-1 & - & - & + & - & + & + \\
\hline 4-17-2 & - & - & + & - & + & + \\
\hline $4-17-3$ & - & - & - & - & + & + \\
\hline 4-17-4 & - & - & + & - & + & + \\
\hline $4-18-2$ & - & - & + & - & - & + \\
\hline 4-18-4 B & - & - & + & - & + & ++ \\
\hline 4-18-4P & $\cdot$ & + & + & - & + & ++ \\
\hline $4-18-7$ & - & - & + & - & - & + \\
\hline 4-19-1 & - & + & + & - & + & + \\
\hline 4-19-3 VB & - & - & + & - & + & + \\
\hline $4-19-3 P$ & - & - & + & - & + & + \\
\hline TOTAL & $0 / 23$ & $7 / 23$ & $18 / 23$ & $2 / 23$ & $17 / 23$ & $21 / 23$ \\
\hline$\%$ & 0 & 30,43 & 78,26 & 8,69 & 73,91 & 91,30 \\
\hline
\end{tabular}

\section{Fermentação Submersa e Atividade Lipolítica}

Antes da fermentação, foi realizado um teste preliminar cultivando a linhagem escolhida (SN2) apenas no meio de inóculo, por um período de $96 \mathrm{~h}$. As amostras foram retiradas em intervalos de 24 horas, para observar a adaptação do micro-organismo ao meio escolhido e se haveria 
produção da enzima lipase. Os resultados obtidos são mostrados na Tabela 2 .

Tabela 2 - Atividade Lipolítica utilizando somente o inóculo.

\begin{tabular}{cccc}
\hline $\begin{array}{c}\text { Tempo } \\
(\mathbf{h})\end{array}$ & $\begin{array}{c}\mathbf{V}_{\mathbf{A}} \\
(\mathbf{m L})\end{array}$ & $\begin{array}{c}\mathbf{V}_{\mathbf{B}} \\
(\mathbf{m L})\end{array}$ & $\begin{array}{c}\text { Atividade } \\
(\mathbf{U} / \mathbf{g})\end{array}$ \\
24 & 16,14 & 16,29 & 0 \\
48 & 17,20 & 16,29 & 2,79 \\
72 & 18,43 & 16,29 & 6,56 \\
96 & 20,17 & 16,29 & 11,89 \\
\hline
\end{tabular}

$\mathbf{V}_{\mathbf{A}}=$ volume da amostra; $\mathbf{V}_{\mathbf{B}}=$ volume do branco; $\mathrm{M}_{\mathrm{NaOH}}=0,01533 \mathrm{M} ; \mathrm{t}=5 \mathrm{~min}, \mathrm{C}_{\mathrm{f}}=1 \mathrm{~mL}$

Como pode ser observado na Tabela 2, no teste preliminar da fermentação a qual utilizou somente o meio de inóculo, o micro-organismo selecionado (SN2) foi capaz de produzir a enzima lipase num período de 96 horas, atingindo uma atividade hidrolítica de aproximadamente $12 \mathrm{U} / \mathrm{g}$, indicando que o fungo é satisfatoriamente um bom produtor dessa enzima.

Baseado nesse resultado foi realizado uma segunda fermentação, com os meios de inóculo por 48 horas e de cultivo por $72 \mathrm{~h}$, em que as amostras foram retiradas em intervalos de 12 horas. Os resultados obtidos são mostrados na Figura 7 e Tabela 3.

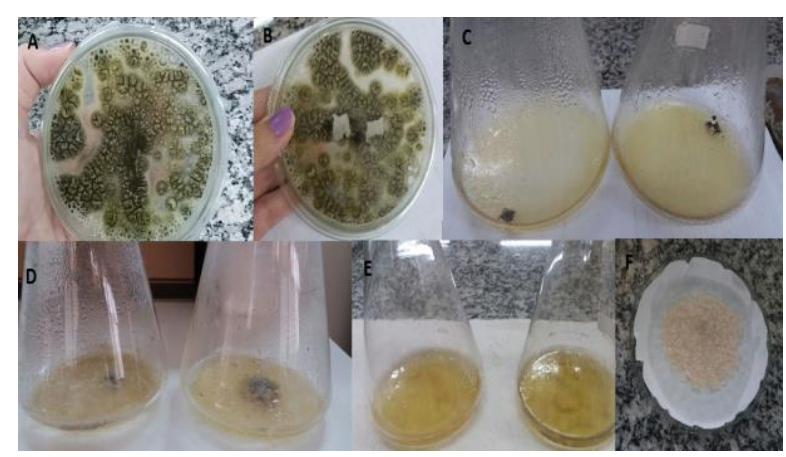

Figura 7 - Etapas da fermentação: A: cultivo do microrganismo; B: corte de área com elevada densidade celular; C: Preparo do inóculo em erlenmeyer de 1L; D: Crescimento do inóculo após $48 \mathrm{~h}$; E: Cultivo em erlenmeyer de $250 \mathrm{~mL} ; \mathbf{F}$ : Filtração do cultivo para análise de peso seco.
Tabela 3 - Atividade lipolítica excretada na fermentação pelo fungo endofítico somente com o meio de cultivo.

\begin{tabular}{cccc}
\hline $\begin{array}{c}\text { Tempo } \\
(\mathbf{h})\end{array}$ & $\begin{array}{c}\mathbf{V}_{\mathbf{A}} \\
(\mathbf{m L})\end{array}$ & $\begin{array}{c}\mathbf{V}_{\mathbf{B}} \\
(\mathbf{m L})\end{array}$ & $\begin{array}{c}\text { Atividade } \\
(\mathbf{U} / \mathbf{g})\end{array}$ \\
0 & 14,87 & 14,19 & 2,31 \\
12 & 14,82 & 14,19 & 2,14 \\
24 & 16,15 & 14,19 & 6,66 \\
36 & 20,73 & 14,19 & 22,24 \\
48 & 21,11 & 14,19 & 23,53 \\
60 & 22,23 & 14,19 & 27,34 \\
72 & 17,84 & 14,19 & 12,41 \\
\hline
\end{tabular}

$\mathrm{M}_{\mathrm{NaOH}}=0,017 \mathrm{M}, \mathrm{t}=5 \mathrm{~min}, \mathrm{C}_{\mathrm{f}}=1 \mathrm{~mL}$

Analisando a Tabela 3, observa-se que o micro-organismo é um bom produtor de lipase atingido uma atividade enzimática de 27,34 U/g, com 60 h de fermentação.

\section{CONCLUSÃO}

A descoberta de celulases, lipases, esterase, fosfatase e $\beta$-fructofuranosidase em uma espécie frutífera característica e exclusiva do cerrado brasileiro valoriza a singularidade da biodiversidade do país e incentiva a produção de culturas extensivas de Marolo. Na caracterização enzimática as atividades obtidas foram: celulolítica $(34,43 \%)$; lipolítica $(78,26 \%)$; fosfatases $(73,91 \%)$; esterásica $(8 \%)$ e $\beta$-fructofuranosidase $(91,3 \%)$. Em relação à fermentação submersa optou-se pela produção de lipases, que é uma enzima bastante aplicada em biocombustível e apresentou uma atividade bastante expressiva de $27,34 \mathrm{U} / \mathrm{g}$ em $60 \mathrm{~h}$ de fermentação.

\section{AGRADECIMENTOS}

À FAPEMIG e UNIFAL-MG pelo apoio financeiro. 


\section{REFERÊNCIAS}

ABRAHÃO NETO, J. Algumas aplicações de enzimas. In: LIMA, U. A.; AQUARONE, E.; BORZANI, W.; SCHMIDELL, W. (Coords.).

Biotecnologia industrial - processos fermentativos e enzimáticos. São Paulo: Edgard Blücher Ltda., 2001. p. 405-412.

AZEVEDO, J.L.; ARAUJO, W.L. Diversity and applications of endophytic fungi isolated from tropical plants. In: GANGULI, B.N.; DESMUCKH, S.K. Fungi: Multifacetated Microbes. New Dehli: Anamaya Publication, 2007. p.189-207.

BATEMAN, D. F.; BASHAM, H. G. Degradation of plant-cell walls and membranes by microbial enzymes. In: HEITEFUSS R.; WILLIAMS, P. H. (Eds.). Encyclopedia of Plant Physiology. New Series: Physiological Plant Pathology. New York: SpringerVerlag, 2001. p. 316-355.

COLEN, C. Isolamento e seleção de fungos filamentosos produtores de lipase. Tese (Doutorado em Ciências dos alimentos) - Faculdade de Farmácia da UFMG, Belo Horizonte, 206 p., 2006.

DILLON, A. Cellulases. In: Enzymes as agents Biotechnology, 243-270, 2004.

DO CANTO, W. L.; MENEZES, T. J. B. Estudos econômicos - alimentos processados. Produção, usos e mercado de enzimas. Campinas: Instituto de Tecnologia de Alimentos, 1995.

FONSECA, A. G.; MUNIZ, I. A. F. Informações sobre a cultura de espécies frutíferas nativas da região de Cerrado. Informe Agropecuário, Belo Horizonte, v. 16, n. 173, p. 12-17, 1992.

HANKIN, L. \& ANAGNOSTAKIS, S.L. The use of solid media for detection of enzyme production by fungi. Mycologia 67:597-607. 1975.

HAWKSWORTH, D.L. The Fungal Dimension of Biodiversity: Magnitude, significance, and Conservation; Mycology Resume. v. 95, p. 641-655, 1991.

LORENZI, H. Árvores brasileiras - Manual de identificação e cultivo de plantas arbóreas nativas do Brasil. Nova Odessa, SP, Editora Plantarum, Vol. II, 1998.

MICHELIN, M. Estudo da glucoamilase e da $\alpha$ amilase produzidas pelo fungo Paecilomyces variotii: purificação, caracterização bioquímica e relações filogenéticas. 2005. 160 f. Dissertação (Mestrado em Ciências) - Universidade de São Paulo, Ribeirão Preto, 2005.
MISAGHI IJ, DONDELINGER CR. Endophytic bacteria in symptom-free cotton plants. Phytopathology 80: 808-811. - doi: 10.1094/Phyto80808, 1990.

PANDEY, A.; NIGAM, P.; SOCCOL, C.R.; SOCCOL, V.T.; SINGH, D.; MOHAN, R. Advances in microbial amylases. Biotechnol. Appl. Biochem., v. 31 , n. 2, p. 135-152, 2000

POLIZELI, M. L. T. M.; JORGE, J. A.; TERENZI, H. F. Pectinase production by Neurospora crassa: purification and biochemical characterization of extracellular polygalacturonase activity. Journal of General Microbiology, London, v. 137, n. 8, p. 18151823, ago. 1991.

SHIN, J.-A.; AKOH, C. C.; LEE, K-T. Enzymatic interesterification of anhydrous butterfat with flaxseed oil and palm stearin to produce low-trans spreadable fat. Food Chemistry, London, v. 120, p. $1-9,2007$

SIERRA, S.A. Simple method for detection of lipolytic activity of microorganisms and some observations on the influence of the contact between cells and fatty substrates. Antonie van Laeuwenhoek 23:15-22. 1957.

SILVA, B. F. Estudo do potencial enzimático de micro-organismos endofíticos para a biotransformação de produtos naturais e análogos sintéticos. 2009. 188f. Tese (Doutorado em Ciências) - Centro de Ciências Exatas e Tecnologia, Universidade Federal de São Carlos, São Carlos, 2009.

SILVA, D. B. et al. Frutas do cerrado. Brasília: Embrapa Informação Tecnológica, 1991.

SILVA, H. G. Substâncias bioativas isoladas dos fungos endofíticos Xylaria sp, Phomopsis cassiae e Acremonium $s p$ associados a espécies vegetais do Cerrado. 2005. 306 f. Tese (Doutorado em Química Orgânica) - Instituto de Química, Universidade Estadual Paulista, Araraquara, 2005.

STROBEL, G.; DAISY, B.; CASTILLO, U.; HARPER, J. Natural products from endophytic microorganisms. Journal of Natural Products, v. 67, n. 2, p. 257-268, 2004.

SOARES, Cleide M. F. et al. Characterization and Utilization of Candida rugosa Lipase Immobilized on Controlled Pore Silica. Applied Biochemistry and Biotechnology, [s.1.], v. 79, n. 1-3, p.745-758, 1999. 
TORRES, F. A. G.; MORAES, L. M. P.; MARCO, J. L.; POÇAS-FONSECA, M. J.; FELIPE, M. S. S. O uso de leveduras e fungos filamentosos para expressão heteróloga de enzimas. In: BOM, E. P. S.; FERRARA, M. A; CORVO, M. L. Enzimas em biotecnologia: produção, aplicações e mercado. Rio de Janeiro: Interciência, cap. 3. p. 55-69, 2008.

\section{Mohamed Ziad Dabaja}

Graduado em Biotecnologia, Universidade Federal de Alfenas, Laboratório de Bioprocessos.

\section{Amanda Varano}

Graduada em Biotecnologia, Universidade Federal de Alfenas, Laboratório de Bioprocessos.

\section{Gustavo Silveira}

Doutor em Química, Universidade Federal de Alfenas, Laboratório de Bioprocessos.

\section{Masaharu Ikegaki}

Professor Doutor Associado na Universidade Federal de Alfenas.

\section{Ernandes Benedito Pereira}

Professor Doutor Associado na Universidade Federal de Alfenas, Programa de Pós Graduação em Engenharia Química. 